\title{
Different effects of nine clausenamide ennatiomers on liver glutathione biosynthesis and glutathione $S$-transferase activity in mice
}

\author{
Yu-qun WU, Li-de LIU, Hua-ling WEI, Geng-tao LIU' \\ Department of Pharmacology, Institute of Materia Medica, Peking Union Medical College \& Chinese Academy of Medical Sciences, Beijing \\ 100050, China
}

\author{
Key words \\ clausenamide; glutathione; $\gamma$-glutamyl- \\ cysteine synthetase; glutathione $S$-trans- \\ ferase

\footnotetext{
${ }^{1}$ Correspondence to Prof Geng-tao LIU. Phn 86-10-6316-5178.

Fax 86-10-6301-7757.

E-mailliugt@imm.ac.cn
} \\ Received 2005-12-12 \\ Accepted 2006-02-28 \\ doi: $10.1111 /$ j.1745-7254.2006.00348.x
}

\begin{abstract}
Aim: To study the effects of nine synthetic clausenamide with different stereo structures on liver glutathione (GSH) biosynthesis and glutathione $S$-transferase (GST) activity in mice. Methods: The nine test compounds were racemic mixtures and their ennatiomers of clausenamide, neoclausenamide and epineoclausenamide. Mice were administered clausenamide $250 \mathrm{mg} / \mathrm{kg}$ once daily for 3 consecutive days, ig, and were killed $24 \mathrm{~h}$ after the last dosing. The mouse liver cytosol GSH and GST were determined with related biochemical methods. Results: Nine clausenamides exhibited different effects on liver GSH and GST. Of nine clausenamides, only $(+)$ and $( \pm$ )clausenamide markedly increased liver cytosol GSH content. The mechanism of increasing liver GSH content of (+)clausenamide is mainly due to stimulating the key limiting enzyme $\gamma$-glutamylcysteine synthetase $(\gamma$-GCS) activity for GSH biosynthesis. The other test clausenamides had no such effect on liver GSH. All of the nine clausenamides induced a significant increase of GST activity. Conclusion: The effects of clausenamide ennatiomers on liver GST and GSH varied with the alterations of their spatial structures. (+)Clausenamide stimulated liver GSH biosynthesis through enhancing $\gamma$-GCS activity.
\end{abstract}

\section{Introduction}

The hepatic drug metabolizing enzymes include phase I and phase II enzymes. In the phase I enzymes, cytochrome $\mathrm{P}-450$ is mainly responsible for the oxidation-reduction metabolic processing of most xenobiotics and also for the inactivation of certain endogenous substances such as steroid hormones. Through phase I metabolism, the formed metabolites with polar groups conjugate with glutathione (GSH) under the catalysis of glutathione $S$-transferase (GST), and the formed complexes are then excreted from the urine and bile. So, there are tight connections among P-450, GST and GSH in the detoxification of the body ${ }^{[1]}$. A number of compounds can affect the P-450, GST and GSH, which results in alternations of the body detoxification function. Our previous study demonstrated that the natural clausenamide, isolated from the leaves of Clausena Lansium (Lour) Skeels ${ }^{[2]}$, significantly protected against hepatotoxicity of $\mathrm{CCl}_{4}$ and induced the hepatic cytochrome P-450 (P-450) in mice ${ }^{[3,4]}$.
The authors further found that the synthetic nine clausenamides and their ennatiomers could induce or inhibit the liver P-450s and P-450-dependent enzymes in mice (data to be published). The purpose of the present paper was to further study the effect of nine synthetic racemic mixtures of clausenamide, neoclausenamide and epineoclausenamide and their corresponding ennatiomers (Figure 1) on liver GSH biosynthesis and GST activity in mice.

\section{Materials and methods}

Animals Male Kunming strain mice weighing $20 \pm 2 \mathrm{~g}$ were obtained from the Experimental Animal Center of Chinese Academy of Medical Sciences, Beijing.

Chemicals Nine clausenamides were totally synthesized and kindly provided by Liang HUANG (Institute of Materia Medica, Chinese Academy of Medical Sciences \& Peking Union Medical College, Beijing). The purity of each compound was over $98 \%$. They were suspended in $0.5 \%$ Tween- 80 
<smiles>CN1C(=O)C(O)[C@H](c2ccccc2)[C@@H]1[C@H](O)c1ccccc1</smiles>

(+)-5 (3R4S5S6R)<smiles>CN1C(=O)[C@H](O)C(c2ccccc2)C1[C@H](O)c1ccccc1</smiles>

$(-)-5(3 S 4 R 5 R 6 S)$
Clausenamide<smiles>CN1C(=O)C(O)[C@H](c2ccccc2)C1[C@H](O)c1ccccc1</smiles>

(+)-6 (3R4S5R6S)<smiles>CN1C(=O)[C@H](O)C(c2ccccc2)[C@@H]1[C@H](O)c1ccccc1</smiles>

(-)-6 (3S4R5S6R)
Neoclausenamide<smiles>CN1C(=O)C(O)[C@H](c2ccccc2)C1[C@H](O)c1ccccc1</smiles>

(+)-16 (3R4S5R6R)<smiles>CN1C(=O)[C@H](O)C(c2ccccc2)[C@H]1[C@H](O)c1ccccc1</smiles>

(-)-16 (3S4R5S6S)
Epineoclausenamide

Figure 1. Chirac structures of clausenamide (5), neoclausenamide (6) and neoclausenamide (16).

before being administered to mice by gavage (ig). Trihydromethyl-aminomethane (Tris), sulfosalicylic acid, 3, 5-diaminobenzoic acid (DABA) 5,5-dithio-bis (2-nitrobenzoic acid (DTNB), $L$-buthionine-[S,R]-sulfoximine $S$-( $n$-butyl)-homocysteine sulfoximine ( $L$-BSO) were purchased from Sigma. All other reagents used were of analytical grade.

Animal treatment Male mice were divided into groups of control, clausenamide, neoclausenamide, epineoclausenamide and their corresponding ennatiomers. The control group contained 6-10 mice, the other groups consisted of 5-8 mice each. The test compound (125 and $250 \mathrm{mg} \cdot 10$ $\mathrm{mL}^{-1} \cdot \mathrm{kg}^{-1}$ ) was given to mice once daily for three consecutive days. The control mice received 5\% Tween $-8010 \mathrm{~mL} / \mathrm{kg}$. All mice were killed by decapitation $24 \mathrm{~h}$ after the last medication. The livers were removed and weighed for preparation of cytosol. The rationale for choosing the dose of clausenamide as well as the timing of administration was based on our study of the hepatoprotective action of clausenamides in mice.

$L$-BSO was dissolved in $0.9 \%$ saline and adjusted to $\mathrm{pH}$ 8.5 with $0.1 \mathrm{~mol} / \mathrm{LNaOH}$ before use. Mice were ip injected a dose of $400 \mathrm{mg} \cdot 20 \mathrm{~mL}^{-1} \cdot \mathrm{kg}^{-1}$ of $L$-BSO. The control mice were ip injected saline $20 \mathrm{~mL} / \mathrm{kg}$.

Preparation of liver cytosol and determination of GST and GSH The procedure for preparation of liver cytosol ${ }^{[5]}$, and the determination of protein ${ }^{[6]}$, liver cytosol GST activity $^{[7]}$, and GSH content ${ }^{[8]}$, and glutathione peroxidase (GSH$\mathrm{px})^{[9]}$ and glutathione disulfide reductase $(\mathrm{GR})^{[10]}$ were performed as described in related references.

Statistical analysis Data are expressed as mean \pm SD. Student's $t$-test was used to calculate the differences between groups. $P<0.05$ was considered to be statistically significant.

\section{Results}

Effects of natural $( \pm)$ clausenamide on liver GSH content and GST activity in mice Oral administration of $( \pm$ )clausenamide $250 \mathrm{mg} / \mathrm{kg}$ to mice once daily for $3 \mathrm{~d}$ induced significant increases in liver cytosol GST activity and GSH content (Table 1).

Table 1. Effects of natural $( \pm$ ) clausenamide and synthesized clausenamide ennatiomers on the liver cytosol GST and GSH in mice. Mean \pm SD. ${ }^{\mathrm{b}} P<0.05,{ }^{\mathrm{c}} P<0.01$ vs control group.

\begin{tabular}{lcccc}
\hline \multicolumn{1}{c}{ Group } & $\begin{array}{c}\text { Dosage } \\
\left(\mathrm{mg} \cdot \mathrm{kg}^{-1}\right)\end{array}$ & $n$ & $\begin{array}{c}\text { GST(CDNB) } \\
\left(\mathrm{mmol} \cdot \mathrm{min}^{-1} \cdot\right. \\
\left.\mathrm{mg}^{-1} \text { protein }\right)\end{array}$ & $\begin{array}{c}\text { Cytosol GSH } \\
\left(\mathrm{nmol} \cdot \mathrm{mg}^{-1}\right. \\
\text { protein })\end{array}$ \\
& & & & \\
& & & & \\
& & 6 & $0.74 \pm 0.08$ & $33.8 \pm 7.1$ \\
Control & 250 & 6 & $0.90 \pm 0.10^{\mathrm{b}}$ & $88.8 \pm 17.7^{\mathrm{c}}$ \\
Natural $( \pm$ )clausenamide & & & & \\
& & 8 & $1.19 \pm 0.16$ & $33.0 \pm 4.8$ \\
Control & 125 & 8 & $1.92 \pm 0.29^{\mathrm{c}}$ & $107.2 \pm 9.4^{\mathrm{c}}$ \\
Synthetic (+)clausenamide & 250 & 8 & $1.76 \pm 0.21^{\mathrm{c}}$ & $108.4 \pm 22.3^{\mathrm{c}}$ \\
$(+)$ Clausenamide & 250 & 8 & $1.81 \pm 0.26^{\mathrm{c}}$ & $70.8 \pm 11.9^{\mathrm{c}}$ \\
$(-)$ Clausenamide & 125 & 8 & $1.63 \pm 0.31^{\mathrm{b}}$ & $34.6 \pm 6.6$ \\
$(-)$ Clausenamide & 250 & 8 & $1.65 \pm 0.24^{\mathrm{c}}$ & $92.5 \pm 29^{\mathrm{c}}$ \\
$( \pm)$ Clausenamide & 250 & 8 & $1.80 \pm 0.39^{\mathrm{c}}$ & $113.9 \pm 34.0^{\mathrm{c}}$ \\
$( \pm)$ Clausenamide & & & & \\
\hline
\end{tabular}

Effects of synthesized clausenamide and its ennatiomers on liver cytosol GST activity and GSH content in mice In this test, three groups of mice were treated with $125 \mathrm{mg} / \mathrm{kg}$, $250 \mathrm{mg} / \mathrm{kg}$ of synthetic $( \pm)$ clausenamide, $(+)$ clausenamide, (-)clausenamide once daily for $3 \mathrm{~d}$, respectively. As a result, the three clausenamides showed different effects on GST and GSH in mice. $( \pm$ )Clausenamide, $(+)$ clausenamide and (-)clausenamide at doses of $250 \mathrm{mg} / \mathrm{kg}$ and $125 \mathrm{mg} / \mathrm{kg}$ all increased GST activity significantly. Only (+)clausenamide 
and $( \pm$ )clausenamide induced a remarkable increase of liver cytosol GSH. The liver GSH content of mice treated with synthetic $(+)$ clausenamide and natural $( \pm$ )clausenamide was almost 2-3 folds of that of control mice. While (-)clausenamide only at $250 \mathrm{mg} / \mathrm{kg}$ increased liver GSH content, and its potency to induce liver GSH is weaker than that of $125 \mathrm{mg} / \mathrm{kg}$ of $(+)$ clausenamide. The group of mice treated with the combined suspension of $125 \mathrm{mg} / \mathrm{kg}$ of both $(+)$ clausenamide and (-)clausenamide, which was mixed just before ig, also induced a significant increase of GSH content and GST activity. The potency of this mixture at the same dosage was essentially corresponding to that of the synthesized $( \pm$ )clausenamide (Table 1).

Effects of neoclausenamide and epineoclausenamide and their ennatiomers on liver cytosol GST activity and GSH in mice Similar experiments for neoclausenamide and epineoclausenamide and their ennatiomers were performed as clausenamide ennatiomers. All of the six compounds induced a significant increase in GST activity, but none of the six test compounds increased the liver cytosol GSH content (Table 2).

Table 2. Effect of ennatiomers of neoclausenamide and epineoclausenamide on liver cytosol GSH and GST in mice. $n=6$. Mean \pm SD. ${ }^{\mathrm{b}} P<0.05,{ }^{\mathrm{c}} P<0.01$ vs control group.

\begin{tabular}{lcc}
\hline $\begin{array}{c}\text { Group } \\
\left(\mathrm{mg} \cdot \mathrm{kg}^{-1} \times 3\right)\end{array}$ & $\begin{array}{c}\text { Cytosol GSH } \\
\left(\mathrm{nmol} \cdot \mathrm{mg}^{-1}\right. \\
\text { protein })\end{array}$ & $\begin{array}{c}\text { GST }(\mathrm{CDNB}) \\
\left(\mathrm{mmol} \cdot \mathrm{min}^{-1}\right. \\
\mathrm{mg}^{-1} \mathrm{protein}^{2}\end{array}$ \\
\hline & $38.12 \pm 22.08$ & $1.05 \pm 0.16$ \\
Control & $38.93 \pm 28.22$ & $1.61 \pm 0.17^{\mathrm{c}}$ \\
$(+)$ Neoclausenamide $(250)$ & $39.80 \pm 36.93$ & $1.30 \pm 0.20^{\mathrm{b}}$ \\
$(-)$ Neoclausenamide $(250)$ & $39.10 \pm 22.96$ & $1.51 \pm 0.18^{\mathrm{c}}$ \\
$( \pm)$ Neoclausenamide $(250)$ & & \\
& $52.20 \pm 18.55$ & $1.54 \pm 0.15$ \\
Control & $55.55 \pm 24.87$ & $2.22 \pm 0.26^{\mathrm{c}}$ \\
$(+)$ Epineoclausenamide (250) & $84.60 \pm 73.06$ & $2.33 \pm 0.37^{\mathrm{c}}$ \\
$(-)$ Epineoclausenamide $(250)$ & $78.54 \pm 57.89$ & $1.92 \pm 0.35^{\mathrm{b}}$ \\
$( \pm)$ Epineoclausenamide $(250)$ & & \\
\hline
\end{tabular}

Effect of $L$-BSO on the increase of liver GSH content induced by $(+)$ clausenamide in mice $L$-BSO is a known specific inhibitor of $\gamma$-glutamyl cysteine synthetase ( $\gamma$-GCS), a limiting enzyme for the biosynthesis of GSH. To investigate whether the increasing effect of $(+)$ clausenamide on the liver GSH is caused by stimulating biosynthesis of GSH or not, $L$-BSO was used as a tool to inhibit the $\gamma$-GCS activity. Mice were administered $125 \mathrm{mg} / \mathrm{kg}$ of $(+)$ clausenamide once daily for different days. As a result, the liver GSH content increased to the higher level at the second day, and did not increase further at the 3 rd day (data not shown). So, in the $L$-BSO experiment, mice were ig administered with 125 $\mathrm{mg} / \mathrm{kg}$ of $(+)$ clausenamide, and simultaneously injected ip $400 \mathrm{mg} / \mathrm{kg}$ of $L$-BSO once daily for $2 \mathrm{~d}$. Another two groups of mice were treated with (+)clausenamide $125 \mathrm{mg} / \mathrm{kg}$ or $L$-BSO $400 \mathrm{mg} / \mathrm{kg}$ alone. The mice were killed on d 3 . A piece of the liver and the left renal were removed for GSH determination as shown in Table 3. $L$-BSO itself showed no significant effect on the liver GSH content, while it blocked (+)clausenamide-induced increase of liver GSH content by $49 \%$. (+)Clausenamide showed no increasing effect on renal GSH content. Whereas $L$-BSO markedly reduced the renal GSH level. The above results suggest that the increase of liver GSH content by $(+)$ clausenamide is the result of stimulating GSH biosynthesis.

Table 3. Effect of $L$-BSO on $(+)$ clausenamide induced increase of liver GSH content in mice. $n=8-10$. Mean $\pm \mathrm{SD}$. ${ }^{\mathrm{c}} P<0.01$ vs control group. ${ }^{\mathrm{e}} P<0.05$ vs $(+)$ clausenamide $125 \mathrm{mg} / \mathrm{kg}$.

\begin{tabular}{lcc}
\hline \multicolumn{1}{c}{ Group } & $\begin{array}{c}\text { Liver GSH } \\
(\mathrm{mmol} / \mathrm{g} \text { liver })\end{array}$ & $\begin{array}{c}\text { Renal GSH } \\
(\mathrm{mmol} / \mathrm{g} \text { renal })\end{array}$ \\
\hline & $5.19 \pm 0.15$ & $3.63 \pm 0.25$ \\
Control & $4.74 \pm 0.57$ & $1.62 \pm 0.21^{\mathrm{c}}$ \\
(+) Clausenamide & $10.53 \pm 1.58^{\mathrm{c}}$ & $3.65 \pm 0.34$ \\
$(+)$ Clausenamide $+L$-BSO & $7.78 \pm 2.58^{\mathrm{ce}}$ & $1.36 \pm 0.40^{\mathrm{c}}$ \\
\hline
\end{tabular}

Effect of $(+)$ clausenamide on the activity of liver GSH peroxidase (GSH-px) and glutathione reductase (GR) in mice Both GSH-px and GR are involved in the redox cycle of GSH and GSSG. This experiment was to investigate whether the increase of liver GSH content by $(+)$ clausenamide is also related to GSHpx and GR, except for the $\gamma$-GCS. Mice were treated with $125 \mathrm{mg} / \mathrm{kg}$ of $(+)$ clausenamide once daily for $2 \mathrm{~d}$, the GSHpx and GR activities in the post-mitochondrial fraction of the livers were determined. The $(+)$ clausenamide significantly increased GR activity, although it did not induce a significant increase of GSHpx activity (Table 4).

\section{Discussion}

The hepatic phase II drug metabolizing enzymes is also a very important part of the major intrinsic detoxicating enzymes in the body, in which GSH conjugated with the formed polar metabolites under the catalysis of GST and the formed complexes were then excreted from the urine and bile. 
Table 4. Effect of $(+)$ clausenamide on liver GSH-px and GR activities in mice. $n=8-10$. Mean \pm SD. ${ }^{\mathrm{c}} P<0.01$ vs control group.

\begin{tabular}{lcc}
\hline \multicolumn{1}{c}{ Group } & $\begin{array}{c}\text { Liver GSH Px } \\
\left(\mathrm{mmol} \cdot \mathrm{min}^{-1} \cdot\right. \\
\left.\mathrm{mg}^{-1} \text { protein }\right)\end{array}$ & $\begin{array}{c}\text { Liver GR } \\
\left(\mathrm{mmol} \cdot \mathrm{min}^{-1}\right. \\
\left.\mathrm{mg}^{-1} \text { protein }\right)\end{array}$ \\
\hline $\begin{array}{l}\text { Control } \\
(+) \text { Clausenamide }\left(125 \mathrm{mg} \cdot \mathrm{kg}^{-1} \times 2\right)\end{array}$ & $2.036 \pm 1.073$ & $20.38 \pm 1.327^{\mathrm{c}}$
\end{tabular}

So, P-450, GST, and GSH are strongly connected in the detoxification of the body ${ }^{[1-14]}$. Glutathione is very important in the maintenance of human health ${ }^{[15]}$. From the present study, it may be seen that the nine clausenamide ennatiomers exerted different inducing effects on liver P-450, GST and GSH. The different effects depended upon the variation of chirac structures of racemic mixture and its corresponding ennatiomers of clausenamide (5), neoclausenamide (6) and neoclausena-mide (16) as shown below (Figure 2).

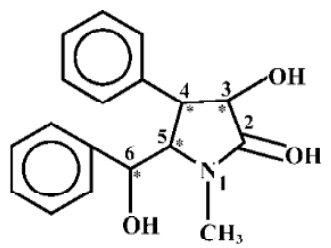

$$
\begin{aligned}
& \text { (+)-5: 3R4S5S6R (-)-5: 3S4R5R6S } \\
& (+)-6: \text { 3R4S5R6S (-)-6: 3S4R5S6R } \\
& \text { (+)-16: 3R4S5R6R (-)-16: 3S4R5S6S }
\end{aligned}
$$

Figure 2. Chirac structures of clausenamide ennatiomers.

The structural variation between clausenamide and epineoclausenamide as well as between neoclausenamide and epineoclausenamide is at C5 and C6 with different configurations, respectively, which results in alternations of their action on the liver P-450, GST, and GSH. In the aspect of liver GST and GSH, all of the nine test compounds were capable of inducing liver GST activity, but their effect on the liver GSH content was completely different. Only clausenamide and its two ennatiomers induced significant increases in liver GSH. In particular, $(+)$ clausenamide was the most active. However, neither neoclausenamide and epineoclausenamide nor their ennatiomers induced an increase of liver GSH content. It appears that the cis-configuration of $\mathrm{C} 4$ and $\mathrm{C} 5$ in clausenamide is a determining structural factor for inducing an increase in liver GSH content, 3R4S5S6R configuration of $(+)$ clausenamide is superior to its 3S4R5R6S configuration of (-)clausenamide in inducing liver GSH. It is known that the hepatic GSH biosynthesis is modulated by multifactors ${ }^{[16]}$, including: (1) the available precursors for GSH synthesis, especially $L$-cysteine $(L-\mathrm{CysH})$; (2) the activity of $\gamma$-glutamylcysteine synthetase ( $\gamma$-GCS) and GSH-synthetase; (3) the rate of redox cycle of GSH and GSSG; and (4) the amount and rate of transportation of GSH and its precursors such as $L$-CysH and $\gamma$-glutamylcysteine ( $\gamma$-GC) into and out from hepatocytes. $\gamma$-GCS is the rate-limiting enzyme in liver GSH biosynthesis. $L$-BSO, a specific inhibitor of $\gamma$-GCS, could markedly block the increase of liver GSH induced by $(+)$ clausenamide, indicating that the increasing effect of $(+)$ clausenamide on liver GSH is mainly due to enhancing the activity of $\gamma$-GCS. However, both GSHpx and GR are involved in the redox cycle of GSH and GSSG. It is interesting to investigate whether the increase of liver GSH content by $(+)$ clausenamide is also related to GSH-px and GR beside the $\gamma$-GCS. The results showed that $(+)$ clausenamide significantly increased GR activity in the post-mitochondrial fraction of livers, but it did not induce significant increase of GSH-px activity. The increase of GR by (+)-clausenamide helps the hepatocytes to reduce more GSSG to GSH, and thereby may partially increase the liver GSH content. The site of stimulatory action of $(+)$ clausenamide on liver GSH biosynthesis is illustrated as follows (Figure 3).

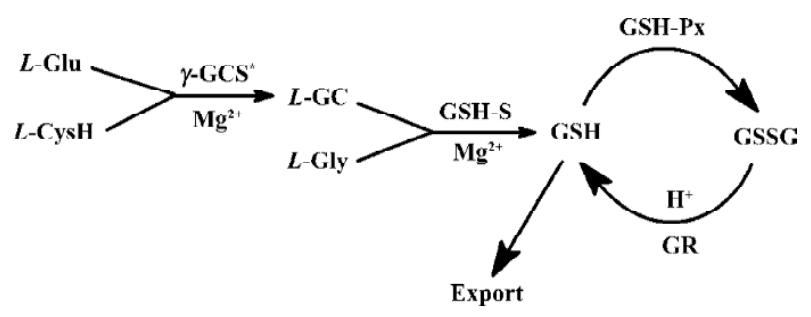

Figure 3. Illustration of biosynthesis and export of GSH in liver and the stimulation of $\gamma$-GCS activity by (+)clausenamide (marked with ${ }^{*}$ ).

In summary, the effects of nine clausenamide ennatiomers on the liver GST and GSH varied with their spatial structures. The C4 and C5 at cis-configuration of the clausenamide can be used particularly for determining structural factors that induce liver GSH biosynthesis. Through this study we understand more of the structure-activity relationship of nine clausenamide ennatiomers on liver GST and GSH. The findings of the present study also provide an example of the importance of different influences of chirac chemicals on the body function. To answer how (+)clausenamide inhibited $\gamma$-GCS or increased GR requires further study at a molecular level. 


\section{Acknowledgement}

The authors are indebted to Prof Liang HUANG for her help in the preparation of the manuscript.

\section{References}

1 Sheehan D, Meade G, Foley VM, Dowd CA. Structure, function and evolution of glutathione transferase: implications for classification of non-mammalian members of an ancient enzyme superfamily. Biochem J 2001; 360: 1-16.

2 Yang MH, Cao YH, Li WX, Yang YO, Chen YY, Huang L. Separation and structure characterization of clausenamide. Acta Pharm Sin 1987; 22: 33-40. Chinese.

3 Liu GT. Effects of some compounds isolated from Chinese medicinal herbs on hepatic microsomal cytochrome $\mathrm{p}-450$ and their potential biological consequences. Drug Met Rev 1991; 23: 439-66.

4 Liu GT, Wei HL, Chen YY, Li WX. Hepatoprotective action of nine constituents isolated from the leaves of Clausena Lansium in mice. Drug Develop Res 1996; 39: 174-8.

5 Lesca P, Lecointe P, Paoletti C, Mansury D. Induction des monooxygenase hepatiques par lellipticine chez le rat: formationde cytochrome p-448, activete hydroxylante. C R Acad Sci 1976; 282: 1457-62.

6 Lowry OH, Rosesrough NJ, Farr AI, Randall RJ. Protein measurement with the Folin phenol reagent. J Biol Chem 1951; 193: 26-9.
7 Habig WH, Pabst MJ, Jakoby WB. Glutathione $S$-transferase: the first enzymatic step in mercapturic acid formation. J Biol Chem 1074; 249: 7130-9.

8 Boyne AF, Ellman GL. A methodology for analysis of tissue sulfhydryl compounds. Anal Biochem 1972; 46: 639-53.

9 Xia YM, Zhu LZ. Method for determination of serum and tissue glutathione peroxidase activity. 1: DTNB direct method. J Hygine 1987; 16: 29-32.

10 Calberg I, Mannervik B. Purification and characterization of the flavoenzyme glutathione reductase from rat liver. J Biol Chem $1975 ; 5475-80$.

11 Eaton DL, Hamel DM. Increase in $\gamma$-glutamylcysteine synthetase activity as a mechanism for butylated hydroxyanisole-mediated elevation of hepatic glutathione. Toxicol Appl Pharmacol 1994; 126: 145-9.

12 Rana SV, Allen T, Singh R. Inevitable glutathione, then and now. Indian J Exp Biol 2002; 40: 706-16.

13 Bounous G, Molson JH. The antioxidant system. Anticancer Res 2003; 23: 1411-5.

14 Pastore A, Federici G, Bertini E, Piemonte F. Analysis of glutathione: implication in redox and detoxification. Clin Chim Acta 2003; 333: 19-39.

15 Townsend DM, Tew KD, Tapiero H. The importance of glutathione in human disease. Biomed Pharmacother 2003; 57: 145-55.

16 Dickinson DA, Forman HJ. Cellular glutathione and thiols metabolism. Biochem Pharmacol 2002; 64: 1019-26. 